\title{
Ethical Leadership: The Effect on Employees
}

\author{
Atiya Alshammari ${ }^{1}$, Naser N. Almutairi ${ }^{1} \&$ Shebaib Fahad Thuwaini ${ }^{1}$ \\ ${ }^{1}$ Management Department, College of Business, Public Authority of Applied Education and Training, Kuwait \\ Correspondence: Naser Almutairi, Management Department, College of Business, Public Authority of Applied \\ Education and Training, Kuwait. Tel: 965-9666-6514. E-mail: kww666@yahoo.com
}

Received: December 22, 2014

Accepted: January 14, $2015 \quad$ Online Published: February 27, 2015

doi:10.5539/ijbm.v10n3p108

URL: http://dx.doi.org/10.5539/ijbm.v10n3p108

\begin{abstract}
Empirical evidence shows that the growing number of business excellence in the contemporary business environment is attributed to the leadership competencies. The frameworks of ethical leadership embody the need to engage the precincts of psychological empowerment with regard to influencing the organizational performance and the moral identity of employees. This study examines the influence that ethical leadership behavior has on the performance, efficiency and productivity of employees. Based on existing literatures and best practices, the study will address the interplay between ethical leadership with competencies, determination, job satisfaction and motivation in addressing the theoretical contributions of ethical leadership on the performance of the organization, practical implication and recommendations son future research.
\end{abstract}

Keywords: ethical leadership, business environment, organizational performance, business excellences, moral identity

\section{Introduction}

The underlying situation in the contemporary business environment has seen many businesses reexamine their strategic acumen by developing a direction that help initiate the foundations of ethical leadership for purposes of efficiency and business profitability. From this perspective, it is clear that ethical leadership reflects the dimension of organizational leadership, behavior and culture with the primary role of leading the organization by making ethical decisions to inherently influence the attitudes and interactions of employees. The meaning of ethical leadership revolves around the practical level of business practice that links the aspects of culture and ethical business practice. This research paper examines the influence that ethical leadership behavior has on the performance, efficiency and productivity of employees based on previous studies, existing literature, empirical evidence and theories. Based on existing literatures and best practices, the paper will address the interplay between ethical leadership with competencies, determination, job satisfaction and motivation in addressing the theoretical contributions of ethical leadership on the performance of the organization, practical implication and recommendations on future research.

\subsection{Definition of Ethical Leadership}

The principles, beliefs and values of the right and wrong characterize the foundation of organizational behavior, thereby formulating the pedestal upon which the leaders influence employees in achieving the goals of the organization (Al-sharafi \& Rajiani, 2013). Bubble (2012) further defines ethical leadership as the process of influencing employees through values, principles and beliefs that extensively border on the accepted norms in the organizational behaviors. These definitions outline the essential element of ethical leadership.

Studies on ethical leadership have portended an increasing relevancy to organizational practice (Hsin-Kuang, Chun-Hsiung \& Dorjgotov, 2012). Neubert, Wu, \& Roberts (2013) argue that the collapse of organizations such as Lehman Brothers and Enron is a succinct pointer on the importance of ethical behavior. This is because lack of ethical behavior in organizational practice is likely to cause harm to the morale of employees, thus invoking the need for regulation from the government on the basics of ethical leadership. According to Rehman (2011), it is evident that the competitive nature of business in the global marketplace has shaped the trajectory whereby the expansion of ethical behavior has been exponential. As a result, the widening scope of ethical concerns in the contemporary businesses is a greatest pointer to the needs of ethical leadership (Ung Hee, Hye Kyoung, \& Young Hyung, 2013).

A study by Caldwell, et al., (2011) found out that the significant issue that challenges modern organizations is the 
reduced application of ethical behavior. Such realization informs that the principles of ethical behavior are widely nonexistent thereby drawing the definition that trust among leadership led to increased motivation among employees and this becomes reflected in the productivity and performance of the organization. In view of this, without ethical leadership, the shadow side of leadership oils strengthened thus increasing the tendency to negatively influence privileges, powers, inconsistency, deception, misplaced loyalties and irresponsibility (Giessner \& Quaquebeke, 2010). As a result, it follows that employees become exposed to these negative influences and generally becomes affected by losing trust as well as integrity in their leader.

Research in the study of ethical leadership leads to the conclusive definition by Kalshoven, Den Hartog, \& De Hoogh (2011) that ethical leaders promote honesty and engage in actions that mirror his values and beliefs. Notably, this perspective embodies an ambiguous s construct making ethical leadership problematic to define. Executives in organizations have a different view of ethical leadership. Their understanding borders on the angle of simply having "good characters and the right values" (Litschka, Suske, \& Brandtweiner, 2011). Such managers admit that by obeying the laws and regulations is the foundation of ethical leadership and thus, it becomes notable that ethical leadership revolves around the primary responsibility of dealing with conflict among employees and demonstrating a guiding platform for instructing them on the right thing to do. This is manifested in the outward display of transformational and servant attitudes. The ethical leaders thus embody inward virtues that direct him in making ethical decisions for the benefit of the wider organization.

\subsection{The Development of Ethical Leadership}

Ethical leadership developed on the backdrop of overlapping and overarching challenges that drove the foundation of leadership research. The formulation of what constitutes leadership and the advent of globalization shaped the emergence of ethical leadership from the primary traditional models of leadership. As McCann and Holt (2009) articulate, the normative question of what is a good leader underscored the effectiveness the value based leaders will play in the contemporary organizational performance. In view of this, the critical theoretical dimension of ethics and leadership became the guiding principles upon which various organizations, and disciplines emphasized on the need of charismatic, transformational as well as visionary leadership as factors hinged on ethics.

The social science perspective of ethical leadership gained momentum in the early 20th $C$ with increased competition and the relation of organizational performance. The dynamics of globalization, as evidenced in the 4-V model of ethical leadership, characteristically formed the basis upon which managers found that employees are significant stakeholders that must be appreciated through distinct strategic direction in a bid to increase their output and personal satisfaction (Nelson, Poms, \& Wolf, 2012). Coupled with the belief that leaders reflected the image of the organization, the growth, popularity and significance of ethical leadership in claiming the core values of the organization and developing a suitable framework that aligns the internal virtue components of leadership with the external organization actions and behaviors for the sole role of promoting the common good of the organization.

Research on leadership and personal experiences around value ethics promoted the institutionalization of ethical leadership. With regard to this, Resick et al. (2011) postulate that the growing desire to embrace integrity formulated the development approach that allowed the establishment and application of ethical leadership within the foundation of managers discovering their core value and developing a vision that would personify the objectives of the organization. Within the 4-V model, the outer commitment of value ethics and the behavioral principles of the organization served as the beginning point where the leadership with a purpose clarion call was established. As a result, ethical leaders have over the years embodied the vision, value and purpose of the organization and the followers as constituents within the broader spectrum of ethical ideals (Avolio, Walumbwa \& Weber, 2009). The foundational objective of ethical leadership has been leaders to connect the goals of the organization within the external stakeholders as well as internal employees. In so doing, ethical leaders work to create a unidirectional structure of management in a bid to maintain a charitable understanding of varied views, values and opinions for the greater good of the organization.

\subsection{Patterns of Ethical Leadership}

In the contemporary business world that is characterized by a host of challenges and unethical practice, the role of value has taken precedence to address the growing level of business malpractice. Bass, et al (2003) argue that the existing pattern of ethical leadership has clearly manifested itself in the situation where leaders extensively devote their energy and time to leading the business process within the spectrum of value creation. Brown, Treviño and Harrison (2005) show that the broader concept of ethical leadership has formed the underlying pattern where leaders are obliged to incorporate the explicit exploitation of values and ethics for a suitable 
leadership framer embedded in ethics. It becomes imperative that this pattern informs the need for effective observation for the underlying shape of business performance and initiate a conversational design where both the manager and the followers establish a perspective of ethical foundation that is not only less complex but also able to emulate the spirit of values and good characters.

Gomez-Mejia, Balkin, \& Cardy (2008) point out that the distinctive pattern of ethical leadership is to embody and articulate the purpose of organizational value. With respect to this, it is clear that leaders in this framework epitomize a morally and compelling narrative of ethics to demonstrate the practical basis of value ethics. Similarly, it is realizable that the challenging business task in most organizations in the present society as characterized in a scenario where everyone aspires of personal satisfaction. Although this has led to the tendency of public display, the revelation of numerous unethical behaviors and scandals demonstrates the selfish egoistic pattern of business leadership. To address this scenario, it is clear that chief executive officers in the contemporary companies must be role models for ethical business leadership in the entire society. To illustrate, it is evident the increase in unethical activities in Citigroup in Japan in 2004 led to the in summary dismissal of several managers upon their ability to accept full responsibility and apologizes to the officials (House, 2004). Within the spectrum of this understanding, it is evident that such a realization resonated with the value systems in Japan and signaled a new era of shared ethical responsibility. In the same breadth, the culture in Citigroup heralded a pattern of ethical leadership where both the managers and employees are expected to take full responsibility for the unethical decisions that may affect the organization.

Moreover, the overriding pattern of ethical leadership is inherent in the increased tendency to pay special attention to developing the best people resource in the organization. The focus on the organizational success as opposed to the personal ego is a key dimension for ethical leadership in understanding their place in the extensive network of stakeholders and constituents (McCray, Gonzalez, \& Darling, 2012). House (2004) reinforces the views of Stacey (2003) by augmenting that ethical leaders emphasize on something bigger than their person as individuals. This is notably the dreams and goals of the organization. In view of this, the realization of the value of business excellences rests on the success of employees as a core competency derivative. For instance, it is evident that in 1998, Roger Enrico, the former CEO of Pepsi demonstrated a bold gestures on how he valued the internal employees of the company. This is clear in his conscious attempt to forego a percentage of his salary on the basis that the company contributes a similar percentage of its turnover for the employees; children scholarship fund (Gomez-Mejia, Balkin, \& Cardy, 2008). Through this framework, it emerges that ethical leadership is not concerned with charities and other donations, but rather through identifying and acting on the lever that increases the loyalty of the employees, their satisfaction and channel it to drive organizational success.

Ethical leadership is about capacity building. The model of value creation is a fairly standardized ethical leadership dimension. As envisioned by McCray, Gonzalez \& Darling (2012), ethical leaders pay special attention to building the capacity of their followers for purpose of sustainability. This is enshrined in the tendency to find and develop the best talented people because it's a moral imperative to help in leadership and create more value to the organization and themselves. This pattern involves the leaders taking ethical principles and factors into consideration in the process of creating sustainable leadership. A case in point is the increasing number of CEOs, who have embarked on programs that evaluates the experiences, skills and talents of employees with considerable regard to integrity. In essence, Stacey (2013) notes that vary many chief executives have initiated ethical compliance approach to solve mentoring challenges. In a bid to effectively realize this pattern, it is imperative for leaders to create a life conversation about values and ethics and extensively the process for creating value for stakeholders. Such conversations must be across all levels of business practice where the tenets of value creation as well as the principles of stakeholders within the wider expectations of the society are routinely examined and evaluated.

In business entities that examines such value conversation, the outcomes border on accountable and responsible performance approach (Tomescu \& Popescu, 2013). As a result. The expectation from employees for the leaders to be accountable implies an efficient model of business excellence and performance measurement where internal and external stakeholders exercise knowledge on alternative drives for realign the inspiration potent for business purpose. To illustrate, the narrative of Jim Burke and the Tylenol product recall in early 1980 best exemplifies the role of value conversation. The short term financial cost of the Tylenol products led to the leaders pulling down all potentially tampered products to maintain the trust of the public and confidence of the employees (Eisenbeiß \& Brodbeck, 2014). This example addresses that critical point to understanding the role of value ethics in ethical behavior.

The mechanism of pushing back to resist the likelihood of the values becoming stale reflects the state 
conceptualization about values and ethics in Johnson and Johnson. Hassan et al. (2013) argue that the perception of legitimate authority is critical in establishing explicit ways in which employees join hand in pushing back the challenges of altering down value ethics as internal process of business operations. Accordingly, this reflects the ideals of Stacey (2013) in formulating the organizational culture that focuses on team work. For example, many executives have used skip level meeting to engage all stakeholders and thus develop a more realistic view of what is happening in the organization.

\subsection{The Core Functions of Ethical Leaders}

The core function of ethical leadership is to construct value paradigms that influence the followers. With regard to this, it is evident that the practical implication of the principles of value ethics rests on the ability of the leader to develop a strategic component of early ethical maturity towards influencing the followers in a bid to enable them pursues success and performance efficiency in the organization. Buble (2012) outlines that in the current global marketplace, organizations have been experiencing disconnect between the beliefs of the leaders and the actions. Such disconnect is characteristically prevalent when ethical dilemmas facing the organizational decision making process. Al-sharafi \& Rajiani (2013) review that the aspect of organizational environment that portend such ethical dilemma is trust between leaders and other respective followers. The small gap that between the actions of the leaders and what he says creates ethical dilemma for the employees. In view of this, it is upon the ethical leadership strategies to close the gap by influence followers through a consistent conduct, moral way of being, proper action and doing what the leader says.

Stacey (2013) brings forth the recommendations that the specific strategies that relate to ethical influential roles of followers and increase in employees trust should mark the primary function of ethical leadership. This strategy must fulfill the functional value of looking within to assess not only the emotional aspect of the organization, but also question the judgment of the leaders in considering others perspectives. Accordingly, it is plausible to note that the demand of the organizational value pretext will be defined through a suitable a suitable course of action. In so doing the leader will effectively anticipate the consequences of the decision weigh competing consideration and successfully recognize the circumstances of ethical dilemma. Within the purviews of strategic approach, the leaders effectively address the emerging ethical dilemmas by laying necessary structures to avoid problems, situational pressures and biases.

In addition, it is plausible to note that the foundation of ethics must reflect the spirit of morality. In view of this, Al-sharafi \& Rajiani (2013) note that employees should be allowed to learn in as much as they observe what their leaders do. In view of this, it is evident that the role of an ethical leader is to personify the espoused values of the organization by building relations that are necessary for harmony. In so doing, it is beyond any reasonable doubt that the purpose of the organization would be realized through frameworks where leaders and followers engage towards mutually beneficial solutions for the organization. The importance of creating a win-win situation that relates to finances is a practice of ethical leadership in sustaining the gains of returns on investment and respect.

The spiritual perspective that shapes a coherent understanding of the function of ethical leaders reflects the role of the leaders in establishing a liberating perspective. According to Hsin-Kuang, Chun-Hsiung \& Dorjgotov (2012), the leaders influence the employees to identify their spiritual niche and connect with the Supreme Being through a paradox that relaxes the central ethical tension. This tension presumably lies in the communal nature of the human being and manifests the inherent need for others through a disposition of self-serving and less egocentric leadership. According to this, the necessary framework that establishes a self-serving design of ethical leadership rests on the ability of the leaders to influence the followers by measuring their actions and outcomes. The programs that survey employees provide the much needed insight into the overall ethical pulse in the organization. With regard to this, the interplay of spiritual connection and employees' influenced actions portray the possible consequence of ethical behaviors which illuminate the features of ethical leadership. In view of this, the leader develops capabilities that consistently gauge the effectiveness of implementing value ethics in the organization.

\subsection{The Influence of Ethical Leaders on Employees}

To understand the influence of ethical leadership on the performance of employees, it is imperative to look at the holistic process where the influence achieves a common good. Resick et al. (2012) argue that the theoretical representation of ethical leadership explains the foundations of trait theory and event theory in situating the roles of leadership. With regard to this, it is evident that the qualities of a leader plays a leading role in developing the transformational goal of leadership concerned with expressing the mission of the organization and laying the necessary foundation for the policies, strategies and procedures for leadership. The use of strategies and 
techniques by the leaders enhances the ability of the leaders to empower the followers and extensively enhancing the employees' self-efficiency. This, according to Nelson, Poms, \& Wolf (2012), works towards leveraging a change of norms, values as well as attitudes that are necessary with the vision of the leaders. Research shows that the ethical style of leadership demonstrates a normative response to the personal actions as well as interpersonal relationships in the organization. This seeks to improve the general conditions of the employee in a bid to enable them respond in the efficient achievement of organizational goals (Stacey, 2013).

The role of ethical leadership in influencing the performance of the employees rests on the pedestal of behavioral motivation, inspiration and individualized consideration. Buble (2012) asserts that the idealized influence allows a more reliable and integrative process of business practice based on moral characterization, strong concerns for self and others and a demonstration of ethical values. In view of this, Nelson, Poms, \& Wolf (2012) highlights a foundational tenet that is deeply embedded in the vision creation and vision fulfillment. With regard to this, it is plausible to note that ethical leadership influences a host of employees by considerable using rewards, formal authority and sanction to influence the compliance behavior of the employee. This approach presumes a transactional design reflecting where the motivation to perform increases the employees' sense of loyalty and selflessness towards the goals of the organization.

The promotion of a reliable and trustworthy conduct among employees is enhanced through reinforcement, two way communication and decision making. This understanding suggests a situation where an ethical leaders withstand the challenges of the organization by emphasizing on the right values and good character in the organization (Hsin-Kuang, Chun-Hsiung, \& Dorjgotov, 2012). The reality of ethical leadership borders on a combination of strength of character and right values, thereby standing a better chance to set examples for other employees to be stakeholders in the organization. This forms the foundation on which the purpose, values and vision of the organization and its constituent reflects the ethical ideals. Within this foundation, the leaders connect the organizational goals with those of the external stakeholders and integral employees.

Imperatively, it is plausible to note that ethical leaders must extensively understand the importance of positive relationship with the stakeholders in the organization. While this forms the gold standard for all the efforts of the organization, it is clear that the quality of relationship must be built on trust and respect as important determinants of success. With regard to this, Resick et al. (2012) outline that ethical leaders play a leading part in understanding such natural form of relationship grow in an environment of integrity, respect and trust justice, equity as well as fairness. As a result, it is important to reflect the views of Nelson, Poms, \& Wolf (2012) that living in harmony which such characteristic principles establishes the efficiency of human enterprise that can flourish and be sustained.

Accordingly, the dimension of ethical leadership should focus on moral values and fairness in decision making while at the same time considering the impact such decisions will have on the organization. This implies that clear communication with employees should be established in order to establish a framework of ensuring the work of employees and how it contributes to the success of the organization. As a result, ethical leaders constantly make efforts that incorporate moral principles in their behavior, values and beliefs embodying a committed to higher organizational purpose enshrined through prudence, persistence and patience (Hsin-Kuang, Chun-Hsiung, \& Dorjgotov, 2012). In conceptualizing the framework of ethical leadership, Stacey (2013) provides a matrix that comprises unethical characterization. This borders of the angle of hypocrisy. In the same fashion, Buble (2012) proposes that leaders must be perceived as people of good moral standing, showing concerns for the welfare of employees and become approachable.

\subsection{Advantages of Ethical Leadership in Public Sector}

Ethical leadership is advantageous to the public sector because it emphasizes on the involvement of the state in certain aspects of the society through corporate social responsibility. Embracing a wide range of activities ranging from security, education, urban planning, administration, health among others, it becomes imperative that the utilization of ethical leadership will enhance the delivery of service within the purviews of equity and fairness. Giessner and Quaquebeke (2010) argue that the integrated approach of leadership allows leaders of public sector to be held accountable to a wide range of stakeholders and citizenry. It follows to note that with public leaders expected to perform in their service delivery by meticulously conforming to the higher standing of personal morality, it is key that the process of public administration will uphold value within the independent exploration of leadership.

In addition, a host of values that are commonly resonated with transformation and transaction of public sector shapes the understanding of ethical values and public expectations thus potentially allowing for incorporation of ethical consideration into the holistic integrated approach to leadership in public sector. According to Rehman 
(2011), ethical leadership in has reinforced mutually appropriate behavior that optimizes idealist concepts of efficiency and business excellences. Evidently, through the foundations of ethical leadership, public sector has been managed in a manner that fosters transparency and reduced corruption, thus contributing to the overall spectrum of ethical responsibility. In view of this, the increasing expectation of leaders and the public to meet a wide array of prototypical standards represents the basis of ethical leadership.

In the era of high profile value lapse in public sector, ethical leadership fosters the frequent utilization and reference to moral judgment (Hsin-Kuang, Chun-Hsiung, \& Dorjgotov, 2012). Rehmann (2011) further contends that the stakeholders have leveled increasing expectation of the ethical stands to carry out a wide array of activities within the perspective of moral good. This increasing awareness, attached to societal value and public interests has been the core principle consideration of ethical leadership and management. It is on this framework that the stakeholders have become more assertive in demanding for transparency and accountability in public sector.

\subsection{The Challenges of Ethical Leadership in Public Sector}

Litschka, Suske, and Brandtweiner (2011) assert that the strategic value of a successful ethical leadership should effort to act with fairness, integrity and socially responsible approach. However, the characteristic environment in which public sector operates challenges the management what is fair in the myriad areas of public activities. The proposed solution to this challenge is anchored on increasing the morale of leaders in emulating the tenets of ethical practice. It emerges that the consistent tension that occurs in the implementation of ethical leadership systems. This is because the wide speared occurrence of naturally egotistical during the process of decision making requires leaders in the public sector to shed overreliance on natural tendencies. Accordingly, it is plausible to note that ethical leaders have been unable to take into account the consequences of their followers when making decisions in public sector. Giessner and Quaquebeke (2010) argues that within this in question, it becomes challenges the overdrive of ethical leadership cling to the value of service delivery, thus reducing the potential harm as the outcome of business process.

Most leaders in public sector are characterized by defensive personality conflicts. This portends a creation of various centers of power aimed at enriching the goals of individual leaders as opposed to the entire organization. Such complication poses ethical concerns making it difficult for leaders to engage in integrative transactional approach of leadership. In light of this, it is clear that the underlying reason for the failure in leaders in public sector occur due to increases selfishness and ignorance. As Buble (2012) notes, it is a common occurrence that such leaders often feel excused from the requirements of moral dispensation. The reasoning that establishes this perspective is the sense of leadership seen as separate from the self of a leader. In light of this, public sector leaders are more likely to excuse themselves from practicing ethical management.

\subsection{The Role of Ethical Leadership in Raising Efficiency in Public Sector}

In public sector, the role of ethical leadership in increasing efficiency rests on the pedestal of ethical leadership behavior. This is built on the model of psychological empowerment where the leader mediates the interplay between the performance, expectation and relationships with the employees. Within the perspective of moral identity, Hsin-Kuang, Chun-Hsiung and Dorjgotov (2012) share the conceptualization that the intermediate influence of ethical leadership in improving efficiency portends a variable of moral identity. According to Rehman (2011), leaders in public sector are mandated to set leading examples on issues of trust and integrity that determines that the activities of the public sector are not detrimental to the values of the society but rather enhance the utility of human needs.

By exhibiting ethical behaviors, leaders in public sector inspire their followers to engage in what is right, good and just. This approach helps in elevating the moral awareness of the followers leading to a highly motivated workforce, high rate of job satisfaction, self-actualization and increased effective in service delivery. In light of this, the views of Litschka, Suske, and Brandtweiner (2011) demonstrate a critical appreciation of contemporary management placing ethical leadership on the axis that encompass the consistence in an effort to foster ethical behavior. In light of this, Giessner and Quaquebeke (2010) point out that through ethical leadership business and activities in public sector have succeeded in investing into more expanding and hybrid public policy initiatives allowing a high production index. With regard to this, it can be concluded that ethical leaders participate in creating the right environment and the necessary condition for a culture of success, transparency and accountability. While this fosters moral development among the followers, it enhances the efficiency in productivity.

Ethical leadership practice in public sector has existed in the basis of strategic reevaluation. The maintenance of ethical leaders has served to enhance the integrated approach that allows leaders to understand the environment 
of their business practice and initiate moral foundation programs on administrative ethics. The primary role of this trajectory is to enhance the spirit of competence coupled with ethical decision making process that drives the public interest, and societal expectations. Evidently, the association of quality production within the purviews of transformational leadership serves the needs of ethical leaders in the public sector (Hsin-Kuang, Chun-Hsiung, \& Dorjgotov, 2012). Through initiatives such as risk taking as well as commitment, it is plausible to note that the systematic reasoning of public risk taking initiative sustains quality commitment added to the public sector ethical climate. With regard to this, it is evident that ethical leaders have focused on aspects of both transactional and transformational leadership to potentially execute clear cut approach that benefits the extensive dimension of service delivery within the environment of the public sector.

\section{Methodology}

A structured approach was concisely used in determining the studies to be reviewed and analyzed. The focus turning on peer reviewed literatures provided the study with the authentic information around the assessment of the effect of the ethical leaders in the performance of the employees in the public sector. As a result, searches of peer reviewed journals and other studies on ethical leadership were conducted in Jstor, Ebscohost and ProQuest databases. The Inclusion criteria were based on all documents, journals, previous studies on ethical leadership and organizational behaviors. This contained generalized information on the effect of the ethical leaders in the performance of the employees in the public sector. However, the literature that was not published within 5 years was excluded. Descriptive search terms including ethical leadership, business environment, organizational performance, business excellences, and moral identity were used to retrieve information and previous studies from online databases and the library.

The implementation of the ethical leadership strategies in the public sector is knitted on the literature review, previous studies, empirical evidence and theoretical concepts applied to research design, research strategy and philosophical approach. Transformational and transactional theoretical research framework pointed to the influence of ethical leadership on the performance management of public sector organization, providing the springboard on which the effectiveness of this research was developed. Theoretical research framework succinctly examined the sociological dimension of the interplay between ethical leadership and organizational performance by reviewing previous studies and exiting literature that the research paper incorporated. The broad purviews of objectivist and subjectivities philosophy enhanced the use of quantitative and qualitative methods of research.

To ascertain the efficiency of ethical leadership and the role it plays in strategic focus of organizational practice, the research borrowed from the functionalist nature of leadership and management analyzing the previous studies and theories of leadership within the spectrum of experimentalism, interpretive and humanist approaches. This succinctly achieved the objective of the study to gather adequate information and perspective to prove the effect of the ethical leaders in the performance of the employees in the public sector

The viability and reliability of the data was developed from the standpoint of legitimizing the conclusions on the degree to which the foundation of the research accurately led to the justification of the conclusion that ethical leadership positively affect the performance of employees in the organization. It is evident that the extent to which the findings of the study established an accurate generalization, the confluence between the theoretical framework and the study results reinforced the conclusion that ethical leadership extensively.

\section{Conclusion}

From the foregoing discussion, it is evident that ethical leadership affects the performance of organizations in public sector. Previous research and the frameworks of transformational leadership prove that ethical leadership affect the performance of the organization. In essence, the qualities of an ethical leader play a leading role in developing the transformational goal of leadership concerned with expressing the mission of the organization and laying the necessary foundation for the policies, strategies and procedures for leadership. The use of strategies and techniques by the leaders enhances the ability of the leaders to empower the followers and extensively enhancing the employees' self-efficiency.

The categorization of ethical leadership in organizational management is a conceptualization of positive relationship that potentially exist on the backdrop of moral values, obligations of leaders and expectation of associated leadership factors. The interplay of such factors provide a meaningful insight into the utilization of ethical considerations within the extensive framework of integrated public sector leadership. The challenges that leaders facing implementing ethical leadership are merely adaptive and serve to create a resolute opportunity needed for integrating transactional and transformational elements of leadership. The contemporary expectations of public leaders are morally responsible and serve in the contribution of a wider environment in which the 
principles of ethical leadership are examined.

\section{Recommendation}

The distinctive pattern of ethical leadership should embody and articulate the purpose of organizational value. With respect to this, it is clear that leaders in this framework epitomizes a morally and compelling narrative of ethics to demonstrate the practical basis of value ethics.

The challenging business task in most organizations in the present society as characterized in a scenario where everyone aspires of personal satisfaction. Although this has leader to the tendency of public display, the revelation of numerous unethical behaviors and scandals demonstrates the selfish egoistic pattern of business leadership. To address this scenario, it is clear that chief executive officers in the contemporary companies must be role models for ethical business leadership in the entire society.

Moreover, the overriding pattern of ethical leadership is inherent in the increased tendency to pay special attention to developing the best people resource in the organization. The focus on the organizational success as opposed to the personal ego is a key dimension for ethical leadership in understanding their place in the extensive network of stakeholders and constituents.

Ethical leaders should emphasis on something bigger than their person as individuals. This is notably the dreams and goals of the organization. In view of this, the realization of the value of business excellences rests on the success of employees as a core competent derivative in ethical leadership.

Ethical leadership should identify and act on the lever that increases the loyalty of the employees, their satisfaction and channel it to driving organizational success.

\section{References}

Al-sharafi, H., \& Rajiani, I. (2013). Promoting Organizational Citizenship Behavior among Employees-The Role of Leadership Practices. International Journal of Business \& Management, 8(6), 47-54.

Avolio, B. J., Walumbwa, F. O., \& Weber, T. (2009). Leadership: Current theories, research and future directions. Annual Review of Psychology, 60, 421-449. http://dx.doi.org/10.1146/annurev.psych.60.110707.163621

Bass, B. M., Avolio, B. J., Jung, D. I., \& Berso, Y. (2003). Predicting Unit Performance by Assessing Transformational and Transactional Leadership. Journal of Applied Psychology, 88, 207-218. http://dx.doi.org/10.1037/0021-9010.88.2.207

Brown, M. E., Treviño, L. K., \& Harrison, D. A. (2005). Ethical leadership: A social learning perspective for construct development and testing. Organizational Behavior and Human Decision Processes, 97, 117-134. http://dx.doi.org/10.1016/j.obhdp.2005.03.002

Buble, M. (2012). Interdependence of Organizational Culture and Leadership Styles in Large Firms. Management: Journal of Contemporary Management Issues, 17(2), 85-97.

Caldwell, C., Dixon, R., Floyd, L., Chaudoin, J., Post, J., \& Cheokas, G. (2012). Transformative Leadership: Achieving Unparalleled Excellence. Journal of Business Ethics, 109(2), 175-187. http://dx.doi.org/10.1007/s10551-011-1116-2

Eisenbeiß, S. A., \& Brodbeck, F. (2014). Ethical and unethical leadership: A cross-cultural and cross-sectoral analysis. Journal of Business Ethics, 122(2), 343-359. http://dx.doi.org/10.1007/s10551-013-1740-0

Giessner, S., \& Quaquebeke, N. (2010). Using a Relational Models Perspective to Understand Normatively Appropriate Conduct in Ethical Leadership. Journal of Business Ethics, 9543-9555.

Gomez-Mejia, L. R., Balkin, D. B., \& Cardy, R. L. (2008). Management: People, Performance, Change (3rd ed.). New York.

Hassan, S., Mahsud, R., Yukl, G., \& Prussia, G. E. (2013). Ethical and empowering leadership and leader $\begin{array}{llll}\text { effectiveness. Journal of } & \text { Managerial }\end{array}$ http://dx.doi.org/10.1108/02683941311300252

House, R. J. (2004). Culture, Leadership, and Organizations: The GLOBE Study of 62 Societies. SAGE Publications, Thousand Oaks.

Hsin-Kuang, C., Chun-Hsiung, L., \& Dorjgotov, B. (2012). The Moderating Effect of Transformational Leadership on Knowledge Management and Organizational Effectiveness. Social Behavior \& Personality: An International Journal, 40(6), 1015-1024. http://dx.doi.org/10.2224/sbp.2012.40.6.1015

Kalshoven, K., Den Hartog, D., \& De Hoogh, A. (2011). Ethical Leader Behavior and Big Five Factors of 
Personality. Journal of Business Ethics, 100(2), 349-366. http://dx.doi.org/10.1007/s10551-010-0685-9

Laasch, O., \& Conaway, R. (2014). Principles of Responsible Management: Global Sustainability, Responsibility. Cengage Learning, USA.

Litschka, M., Suske, M., \& Brandtweiner, R. (2011). Decision Criteria in Ethical Dilemma Situations: Empirical Examples from Austrian Managers. Journal of Business Ethics, 104(4), 473-484. http://dx.doi.org/10.1007/s10551-011-0922-x

Lu, X. (2014). Ethical Leadership and Organizational Citizenship Behavior: The Mediating Roles of Cognitive and Affective Trust. Social Behavior and Personality, 42(3), 379-389. http://dx.doi.org/10.2224/sbp.2014.42.3.379

McCann, J., \& Holt, R. (2009). Ethical Leadership and Organizations: An Analysis of Leadership in the Manufacturing Industry Based on the Perceived Leadership Integrity Scale. Journal of Business Ethics, 87(2), 211-220. http://dx.doi.org/10.1007/s10551-008-9880-3

McCray, J. P., Gonzalez, J. J., \& Darling, J. R. (2012). Transformational Crisis Management. Developing Efficacy Beliefs for Ethics and Diversity Management. Academy of Management Learning \& Education, 11(1), 49-68.

Neubert, M., Wu, C., \& Roberts, J. (2013). The Influence of Ethical Leadership and Regulatory Focus on Employee Outcomes. Business Ethics Quarterly, 23(2), 269-296. http://dx.doi.org/10.5840/beq201323217

Raja, A., \& Palanichamy, P. (2011). Leadership Styles and Its Impact on Organizational Commitment. Journal of Commerce, 3(4), 15-23.

Rehman, R. (2011). Role of Emotional Intelligence on the Relationship among Leadership Styles, Decision Making Styles and Organizational Performance: A Review. Interdisciplinary Journal of Contemporary Research in Business, 3(1), 409-416.

Resick, C., Martin, G., Keating, M., Dickson, M., Kwan, H., \& Peng, C. (2011). What Ethical Leadership Means to Me: Asian, American, and European Perspectives. Journal of Business Ethics, 101(3), 435-457. http://dx.doi.org/10.1007/s10551-010-0730-8

Stacey, D. R. (2003). Strategic Management and Organisational Dynamics. London: Prentice Hall.

Tomescu, M., \& Popescu, M. A. (2013). Ethics And Conflicts of Interest In The Public Sector. Contemporary Readings in Law and Social Justice, 5(2), 201-206.

Ung Hee, L., Hye Kyoung, K., \& Young Hyung, K. (2013). Determinants of Organizational Citizenship Behavior and Its Outcomes. Global Business \& Management Research, 5(1), 54-65.

\section{Copyrights}

Copyright for this article is retained by the author(s), with first publication rights granted to the journal.

This is an open-access article distributed under the terms and conditions of the Creative Commons Attribution license (http://creativecommons.org/licenses/by/3.0/). 